\title{
Long-term pulmonary function after thoracic sympathectomy
}

\author{
Miguel A. Ponce González, MD, ${ }^{a}$ Gabriel Julià Serdà, MD, ${ }^{a}$ Norberto Santana Rodríguez, MD, \\ Pedro Rodríguez Suárez, MD, ${ }^{\mathrm{b}}$ Gregorio Pérez Peñate, MD, ${ }^{\mathrm{a}}$ Jordi Freixinet Gilart, MD, ${ }^{\mathrm{b}}$ and \\ Pedro Cabrera Navarro, $\mathrm{MD}^{\mathrm{a}}$
}

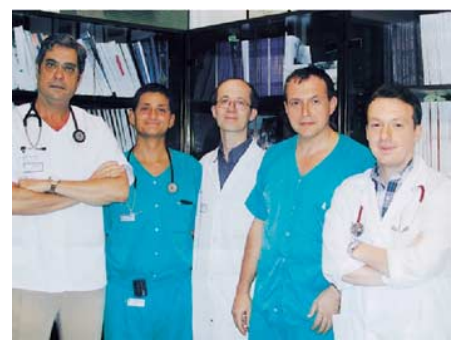

Background: The purpose of this study was to evaluate the long-term and midterm effects of thoracic sympathectomy on pulmonary function and to assess the influence of the sympathetic nervous system on bronchomotor tone.

Methods: Thirty-seven consecutive patients were diagnosed with primary hyperhidrosis requiring thoracic sympathectomy and were included in this study. Spirometry and methacholine challenge testing were performed before and 3 months after surgery. To assess the long-term effects of the intervention, another spirometric study was performed 1 year later.

Results: Spirometry 3 months after surgery showed a significant decrease in the forced vital capacity $(-5.2 \%)$, the forced expiratory volume in the first second $(-6.1 \%)$, and the forced expiratory flow between $25 \%$ and $75 \%$ of vital capacity $(-5.1 \%)$. Whereas methacholine challenge testing before surgery was positive in 3 subjects ( 2 of whom were asthmatic), it was positive in 6 patients after the procedure; differences were not statistically significant. After 12 months, forced vital capacity started recovering, and forced expiratory volume in the first second and forced expiratory flow rate $25 \%$ to $75 \%$ showed a sustained and significant reduction $(-2.8 \%$ and $-11.2 \%$, respectively); however, patients remained asymptomatic.

Conclusions: We conclude that thoracic sympathectomy generates a mild, although significant, impairment of the bronchomotor tone, with no clinical consequences. These results suggest that the sympathetic nervous system is involved in pulmonary bronchomotor tone.

From the Departments of Pulmonary Medicine $^{\mathrm{a}}$ and Thoracic Surgery, ${ }^{\mathrm{b}}$ Hospital Universitario de Gran Canaria Dr Negrín, Las Palmas de Gran Canaria, Spain.

Received for publication July 3, 2004; accepted for publication Aug 23, 2004.

Address for reprints: Miguel A. Ponce González, MD, Department of Pulmonary Medicine, Hospital Universitario de Gran Canaria Dr Negrín, C/ Barranco de la Ballena s/n, 35020, Las Palmas de Gran Canaria, Spain (E-mail: migp@arrakis.es).

J Thorac Cardiovasc Surg 2005;129:1379-82

$0022-5223 / \$ 30.00$

Copyright $\odot 2005$ by The American Association for Thoracic Surgery

doi:10.1016/j.jtcvs.2004.08.026
$\mathrm{P}$ rimary hyperhidrosis is characterized by excessive idiopathic eccrine sweating. It stems from a dysfunction of the autonomic nervous system that is mediated by cholinergic sympathetic fibers. ${ }^{1}$ It most frequently affects the upper limbs (palmar and axillary zones). The definitive treatment of hyperhidrosis is the complete excision, or the ablation with electrocautery or laser, of the T2 and T3 sympathetic ganglia in palmar forms, with the additional excision of the T4 ganglion in axillary forms. Video-assisted endoscopic thoracic sympathectomy (TS) was first described by $\mathrm{Kux}^{2}$ in 1954, and its further development in the 1990s made it suitable as the treatment of choice for primary hyperhidrosis, given the good results and the minimal morbidity and mortality associated with the procedure. ${ }^{3}$

The sympathetic trunks are 2 ganglionic nervous cords comprising several segments: cervical, thoracic, abdominal, and pelvic. The pulmonary sympathetic innervation derives mainly from the thoracic sympathetic chain (T2 to T8), but there are also fascicles from the cervical sympathetic chain (cervicothoracic branches), the stellate ganglion, and the cardiac plexus and fibers from intercostal nerves ${ }^{4}$ 


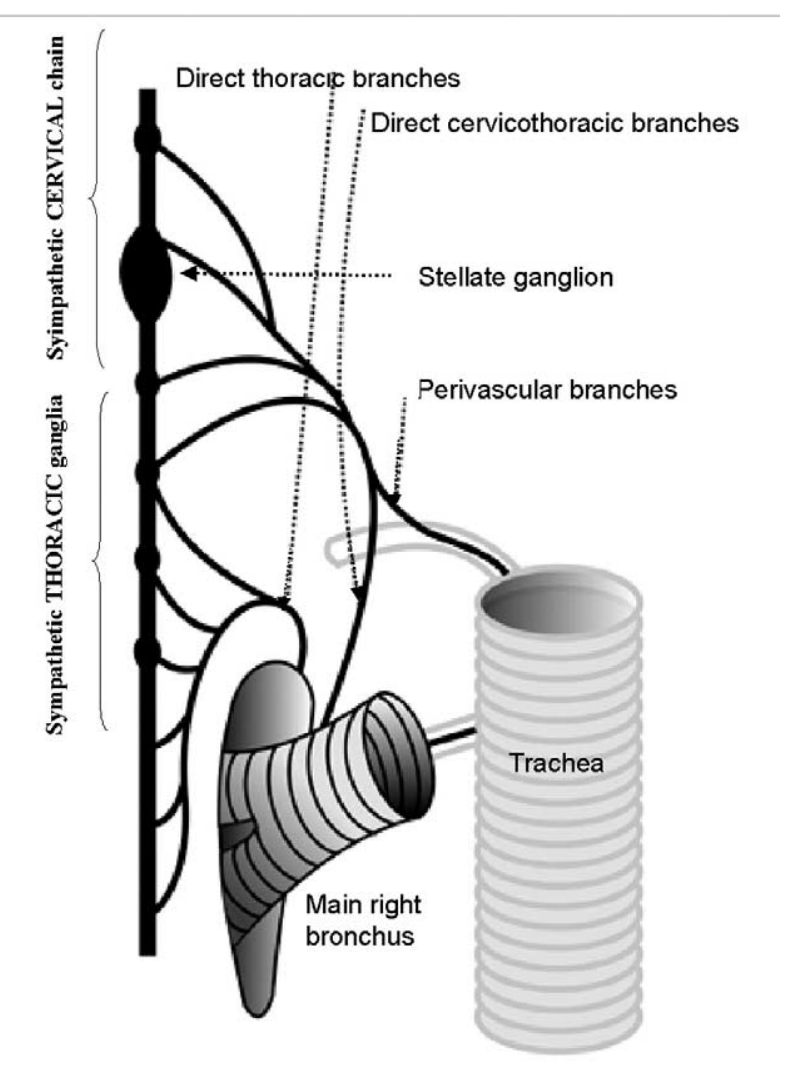

Figure 1. Diagram of pulmonary innervation derived from the cervicothoracic sympathetic chain.

(Figure 1). Therefore, the TS procedure leads to a partial sympathetic pulmonary denervation. ${ }^{5}$

The parasympathetic nervous system (PNS) regulates the bronchomotor tone through the vagus nerve and is involved in other functions, such as glandular secretion. However, the role of the PNS in bronchomotor tone is not fully understood. It is generally accepted that bronchomotor tone in humans is not controlled by sympathetic nervous system (SNS) innervation but by circulating mediators and membrane receptors. ${ }^{6}$ Some authors consider that the SNS helps to modulate the bronchomotor tone, which exhibits a cholinergic preponderance, particularly in conditions with increased tone, such as bronchial asthma. ${ }^{7}$ Moreover, sympathetic innervation is less abundant and comprises smaller fascicles than parasympathetic innervation. ${ }^{4,7}$ However, some studies show that sympathetic innervation reaches even the distal area, because amyelinic sympathetic nervous fibers have been detected within bronchiolar smooth muscle and alveolar ducts. ${ }^{8}$ This has been confirmed by electron microscopy, which provided evidence for the presence of adrenergic nerves in the lower respiratory tract. ${ }^{9}$
Taking advantage of the partial sympathetic denervation, we studied the effects of TS on pulmonary function and determined whether a sympathetic/parasympathetic imbalance could contribute to impairment of the bronchomotor tone.

\section{Patients and Methods \\ Patients}

The sample included 37 consecutive patients with primary hyperhidrosis unresponsive to conservative treatment and for whom the indication of surgical treatment by video-assisted thoracoscopic sympathectomy was ultimately established. The study protocol was approved by the ethics committee at our institution.

\section{Pulmonary Function Tests}

Forced spirometry was performed before and 3 months after surgery in all patients. Thirty-two patients had a new spirometry test 1 year after the TS. The same spirometer was used throughout the study (Master Screen; Jaeger, Wuerzburg, Germany), and the American Thoracic Society guidelines for spirometry were followed..$^{10}$ Recorded parameters were forced vital capacity (FVC), forced expiratory volume in the first second $\left(\mathrm{FEV}_{1}\right)$, peak expiratory flow (PEF), and forced expiratory flow during the middle half of FVC (FEF 25\%-75\%). A methacholine challenge test was also performed before and 3 months after surgery, according to the American Thoracic Society standards. ${ }^{11}$ This was methacholine testing with a dosimeter inhalation protocol (Jaeger). The test started with the administration of saline followed by increasing concentrations of methacholine $(0.195,0.39,1.56,6.25,12.5$, and $25 \mathrm{mg} / \mathrm{mL}$ ). Thirty and ninety seconds after the last inhalation, flow-volume curves were obtained to calculate $\mathrm{FEV}_{1}$. The test was considered positive when an equal or greater than $20 \%$ decrease in postinhalation $\mathrm{FEV}_{1}$ was observed and the $\mathrm{PC}_{20}$ (provocative methacholine concentration causing a $20 \%$ decrease in $\mathrm{FEV}_{1}$ from baseline) was established.

\section{Video-Assisted Thoracoscopic Sympathectomy}

Video-assisted thoracoscopic sympathectomy was performed under general anesthesia with selective bronchial intubation with a double-lumen endotracheal tube. The patient was placed in supine position with both arms in abduction. Two incisions of 5 and 11.5 mm were made $3 \mathrm{~cm}$ apart on the medial and anterior axillary lines, respectively. The sympathetic chain was electrocoagulated with a video-endoscope and an endodissector between T2 and T3 for palmar hyperhidrosis, T3 and T4 for axillary hyperhidrosis, and $\mathrm{T} 2$ and T4 for palmar and axillary hyperhidrosis. A pleural drain was inserted and removed after lung expansion in the operating room. The patient was transferred to a recovery room, where a chest radiograph was obtained to verify complete lung expansion.

\section{Statistical Analyses}

The pulmonary function data are expressed as mean and SD. Comparisons between the methacholine challenge testing results before and after TS were performed by a $\chi^{2}$ test. A paired Student $t$ test was performed to compare the pulmonary function data of the 37 patients before and 3 months after surgery. Finally, the analysis of variance test for repeated measures was applied to analyze the 
TABLE 1. Changes in pulmonary function 3 months after surgery

\begin{tabular}{lccc}
\hline Variable & $\begin{array}{c}\text { Before TS } \\
\text { (mean } \pm \text { SD) }\end{array}$ & $\begin{array}{c}\text { 3 mo after TS } \\
\text { (mean } \pm \text { SD) }\end{array}$ & $\boldsymbol{P}$ value \\
\hline FVC (L) & $4.21 \pm 0.81$ & $4.01 \pm 0.77$ & $<.05$ \\
FVC (\%) & $107 \pm 11.7$ & $101.8 \pm 9.6$ & $<.05$ \\
$\mathrm{FEV}_{1}(\mathrm{~L})$ & $3.72 \pm 0.68$ & $3.57 \pm 0.66$ & $<.05$ \\
$\mathrm{FEV}_{1}(\%)$ & $111.1 \pm 13.4$ & $105 \pm 11.7$ & $<.05$ \\
$\mathrm{FEF}_{25-75}(\mathrm{~L} / \mathrm{s})$ & $4.18 \pm 1.08$ & $4.01 \pm 1.1$ & $<.05$ \\
$\mathrm{FEF}_{25-75}(\%)$ & $103.4 \pm 25.3$ & $98.3 \pm 28.7$ & $<.05$ \\
$\mathrm{PEF}(\mathrm{L})$ & $8.23 \pm 2.03$ & $8.55 \pm 2.09$ & .11 \\
\hline
\end{tabular}

$T S$, Thoracic sympathectomy; FVC, forced vital capacity; $F E V_{1}$, forced expiratory volume in the first second; $F E F_{25-75}$, forced expiratory flow during the middle half of FVC; $P E F$, peak expiratory flow.

pulmonary function data obtained from the 32 patients 12 months after surgery. The Bonferroni test was used as a post hoc test.

\section{Results}

The study population consisted of 28 female and 9 male patients with a mean age of 22.5 years (range, 15-50 years). Two patients had asthma but were asymptomatic and required no bronchodilators. None of the patients was taking any medication with cardiopulmonary effects, and none of them was a smoker. No other patients, besides the 2 with asthma, had any respiratory disease.

After TS, all patients fully recovered from hyperhidrosis, which confirmed the interruption of the sympathetic chain and the resulting partial pulmonary denervation. There were no respiratory complications except for a pneumothorax in 1 patient. Spirometric parameters before surgery were within the normal range (Table 1).

The methacholine challenge testing result was positive in 3 patients, 2 of whom were known to have asthma. In the third patient, the result was considered a false positive, because he had recently had a flulike syndrome.

Three months after the surgery, significant reductions in $\operatorname{FVC}(0.193 \pm 0.273 \mathrm{~L} ;-5.2 \%), \mathrm{FEV}_{1}(0.150 \pm 0.212 \mathrm{~L}$; $-6.1 \%)$, and FEF $25 \%$ to $75 \%(0.170 \pm 0.458 \mathrm{~L} / \mathrm{s} ;-5.1 \%)$ were observed (Table 1). The PEF did not show significant differences. Regarding the respiratory system, the patients remained totally asymptomatic. The methacholine challenge testing 3 months after surgery was positive in 6 patients ( 2 of whom were known to have asthma). The estimated $\mathrm{PC}_{20}$ for the 4 patients was always higher than 2 $\mathrm{mg}(2.599,2.343,2.855$, and $2.510 \mathrm{mg})$. The observed differences were not statistically significant.

In 32 of the 37 patients who started the study, control spirometry was performed 12 months after surgery. The results showed a slight recovery in FVC $(3.99 \pm 0.70 \mathrm{~L}$; $+1.5 \%$ ), which seemed to be nonsignificant. Significant reductions in $\mathrm{FEV}_{1}(3.43 \pm 0.64 \mathrm{~L} ;-2.8 \%)$ and $\mathrm{FEF} 25 \%$ to $75 \%(3.59 \pm 1.15 \mathrm{~L} / \mathrm{s} ;-11.2 \%)$ were observed, com-
TABLE 2. Changes in pulmonary function 3 and 12 months after surgery

\begin{tabular}{lccc}
\hline Variable & $\begin{array}{c}\text { Before TS } \\
\text { (mean } \pm \text { SD) }\end{array}$ & $\begin{array}{c}\text { 3 mo after TS } \\
\text { (mean } \pm \text { SD) }\end{array}$ & $\begin{array}{c}\text { 12 mo after TS } \\
\text { (mean } \pm \text { SD) }\end{array}$ \\
\hline FVC (L) & $4.12 \pm 0.75$ & $3.96 \pm 0.73^{*}$ & $3.99 \pm 0.70$ \\
FVC (\%) & $105.4 \pm 11.61$ & $101.4 \pm 10^{*}$ & $102.9 \pm 13$ \\
$\mathrm{FEV}_{1}(\mathrm{~L})$ & $3.65 \pm 0.67$ & $3.52 \pm 0.67^{*}$ & $3.43 \pm 0.64^{*}$ \\
$\mathrm{FEV}_{1}(\%)$ & $109.9 \pm 13.4$ & $105.2 \pm 12.4^{*}$ & $102.4 \pm 16.7^{*}$ \\
$\mathrm{FEF}_{25-75}(\mathrm{~L} / \mathrm{s})$ & $4.17 \pm 1.13$ & $4.02 \pm 1.22$ & $3.59 \pm 1.15^{*}$ \\
$\mathrm{FEF}_{25-75}(\%)$ & $102.3 \pm 28.2$ & $99 \pm 28.4$ & $87.8 \pm 30.1^{*}$ \\
$\mathrm{PEF}_{(\mathrm{L})}$ & $8.07 \pm 2.06$ & $8.49 \pm 2.14$ & $7.68 \pm 1.59$ \\
\hline
\end{tabular}

$T S$, Thoracic sympathectomy; FVC, forced vital capacity; $F E V_{1}$, forced expiratory volume in the first second; $F E F_{25-75}$, forced expiratory flow during the middle half of $\mathrm{FVC}$; $P E F$, peak expiratory flow. $* P \leq .05$ compared with pre-TS values.

pared with the values obtained 3 months after TS. Once again, the differences in PEF were not statistically significant (Table 2). Patients remained asymptomatic 12 months after TS.

\section{Discussion}

Studies describing impairment of pulmonary function after TS are scarce. Such studies have evaluated short-term and midterm pulmonary function changes $(1,3$, and 6 months after TS). ${ }^{5,12-14}$ This study aimed to confirm the few existing data on pulmonary function after TS and to assess the potential effects of this procedure on bronchial reactivity. We studied patients 1 year after surgery to provide new data from which conclusions were drawn regarding the role of SNS in respiratory physiology and to test whether TS is a safe technique devoid of long-term risks.

The first 2 studies on pulmonary function after TS were published by Molho and colleagues ${ }^{12,13}$ in the 1970 s and 1980s. They performed and compared sympathectomy with thoracotomy through either the supraclavicular or the transaxillary approach and observed a reduction in pulmonary volumes and flows at 3 weeks and 3 and 6 months after surgery. The surgical technique may have partially contributed to this decrease, as demonstrated by Furrer and associates, ${ }^{15}$ who found that pulmonary function became close to normal 4 months after surgery. Therefore, the observed reduction can be ascribed, at least in part, to thoracotomy, which causes a restrictive pattern in pulmonary function tests. ${ }^{15}$ However, the persistence of low volumes and flows 6 months after surgery also suggests an impairment of the bronchomotor tone, as demonstrated in our study.

Tseng and Tseng ${ }^{14}$ and Noppen and Vincken ${ }^{5}$ conducted studies in which TS was performed with video-assisted endoscopy. The first study showed a reduction in $\mathrm{FEV}_{1}$ $(-6.1 \%)$, FVC $(-2.3 \%)$, and FEF $75 \%$ (-8\%) 1 month after the procedure. Even for minimally invasive operations, the postsurgical period allowed was excessively short, and 
this left open the possibility that changes were directly related to the surgical technique. In the second study, pulmonary function tests performed 3 months after the procedure revealed a significant reduction in $\mathrm{FEV}_{1}(-2.8 \%)$, FVC $(-1.9 \%)$, and FEF $75 \%(-6.5 \%)$. These values persisted 6 months later in the case of $\mathrm{FEV}_{1}(-3 \%)$ and FEF $75 \%(-8.6 \%)$, whereas FVC showed an initial recovery.

Our data on $\mathrm{FEV}_{1}$ and midexpiratory flows confirmed the 3 -month postoperative findings from Noppen and Vincken. ${ }^{5}$ Moreover, we observed a sustained and significant decrease in $\mathrm{FEV}_{1}$ and FEF 25\% to $75 \% 12$ months after the surgical intervention. We consider that a postoperative period of 1 year is long enough to determine whether TS can generate bronchomotor tone disturbances independently of the surgical trauma itself. A reduction in FVC after 3 months could be due to restrictive constraints imposed by the surgical technique, because this parameter recovered by 12 months, whereas the reductions in $\mathrm{FEV}_{1}$ and $\mathrm{FEF} 25 \%$ to $75 \%$ remained. ${ }^{15}$ The finding that $\mathrm{FVC}$ returned to a preoperative range, together with a persistent reduction in $\mathrm{FEV}_{1}$ and $\mathrm{FEF}$ $25 \%$ to $75 \%$, indicates that partial sympathetic denervation is responsible for the long-term increased bronchomotor tone. Such changes, although significant, are small and clinically irrelevant. None of the 32 patients had respiratory symptoms. They all had adequate exercise tolerance and good general conditions. Together, these results allow us to conclude that TS is a safe exploratory procedure that is devoid of long-term secondary respiratory effects.

With the aim of assessing SNS/PNS balance, we also performed methacholine challenge testing in the patients who underwent TS. Our starting hypothesis was that sympathetic denervation would cause an increase in cholinergic tone, so we could expect a significant number of positive results 3 months after surgery. However, the differences observed were not significant. This result is consistent with the less abundant and smaller fascicles of sympathetic innervation compared with parasympathetic innervation. ${ }^{4,7}$ Also, TS generates partial sympathetic denervation with some remaining cervicothoracic branches, with the capacity to innervate the bronchial tree. ${ }^{4}$ Alternatively, methacholine could stimulate cholinergic receptors and induce a PNSmediated bronchial constriction. In this way, methacholine challenge testing evaluates the role of PNS on the airways, which is theoretically normal in patients subjected to TS. Among our patients, there were 2 known to have asthma in stable condition that did not require continuous medication. In these patients, the methacholine testing was positive before and after TS; during follow-up, they experienced neither particular respiratory symptoms nor the need for rescue bronchodilators, which would suggest a worsening of their background condition. Among the patients studied, 3 with a prior negative methacholine challenge test had a positive result after surgery. We have no clear explanation for this observation; the patients were asymptomatic, and their $\mathrm{PC}_{20}$ values were high-close to the maximal dose establishing the test as positive ${ }^{11}$ - suggesting that these values could lay within the variability range attributable to the test. ${ }^{16}$

The results from our research enabled us to conclude that TS is a safe technique in the long term, because the reduction of volumes and flows is minimal and clinically irrelevant. We also demonstrated that SNS is involved in pulmonary bronchomotor tone, at least in patients with primary hyperhidrosis. The evidence for this is the sustained and significant long-term decrease in $\mathrm{FEV}_{1}$ and FEF $25 \%$ to $75 \%$. To our knowledge, this is the first report in the literature assessing long-term effects of TS on pulmonary function 1 year after surgery.

\section{References}

1. Shih CJ, Wu JJ, Lin MT. Autonomic dysfunction in palmar hyperhidrosis. J Auton Nerv Syst. 1983;8:33-43.

2. Kux E. Thorakoskopische Eingriffe am Nervensystem. Stuttgart: Georg Thieme Verlag; 1954.

3. Neelan D, Shannon H, Mary W, Lynne H, Syma P, Meyer DM, et al. Thoracoscopic sympathectomy for hyperhidrosis: indications and results. Ann Thorac Surg. 2004;77:410-4.

4. Lazorthes G. Cadena simpática laterovertebral. In: Lazorthes G, editor. Descripción, sistematización y exploración del sistema nervioso autónomo. Capítulo XXIV, Barcelona: Toray-Mason; 1976. p. 325-57.

5. Noppen M, Vincken W. Thoracoscopic sympathicolysis for essential hyperhidrosis: effects on pulmonary function. Eur Respir J. 1996;9: 1660-4.

6. Richardson J, Beland J. Non adrenergic inhibitory nervous system in human airways. J Appl Physiol. 1976;41:764-71.

7. Barnes PJ. Neural control of human airways in health and disease. Am Rev Respir Dis. 1986;134:1289-314.

8. Testud L. Pulmones: vasos y nervios a nivel de lobulillos pulmonares. In: Testud L, Latarjet A, editors. Tratado de anatomía humana. Tomo 3, volume III, 9th ed. Barcelona: Salvat; 1988. p. 995-1002.

9. Laitinen A, Partanen M, Hervonen A. Electron microscopy study on the innervation of the human lower respiratory tract: evidence of adrenergic nerves. Eur J Respir Dis. 1985;67:208-15.

10. Standardization of spirometry, 1994 update. American Thoracic Society. Am J Respir Crit Care Med. 1995;152:1107-36.

11. Crapo RO, Casaburi R, Coates AL, Enright PL, Hankinson JL, Irvin $\mathrm{CG}$, et al. Guidelines for methacholine and exercise challenge testing-1999. This official statement of the American Thoracic Society was adopted by the ATS Board of Directors, July 1999. Am J Respir Crit Care Med. 2000;161:309-29.

12. Molho M, Kurchin A, Ohry A, Bass A, Adar R. Pulmonary functional abnormalities after upper dorsal sympathectomy. Am Rev Respir Dis. 1977;116:879-83.

13. Molho M, Shemesh E, Gordon D, Adar R. Pulmonary functional abnormalities after upper dorsal sympathectomy. Chest. 1980;77:651-5.

14. Tseng MY, Tseng JH. Thoracoscopic sympathectomy for palmar hyperhidrosis: effects on pulmonary function. J Clin Neurosci. 2001;8: 539-41.

15. Furrer M, Rechsteiner R, Eigenmann V, Signer C, Althaus U, Ris H. Thoracotomy and thoracoscopy: postoperative pulmonary function, pain and chest wall complaints. Eur J Cardiothorac Surg. 1997;12: 82-7.

16. Balzano G, Delli Carri I, Gallo C, Cocco G, Melillo G. Intrasubject between-day variability of PD20 methacholine assessed by the dosimeter inhalation test. Chest. 1989;95:1239-43. 